\title{
Real Time Telephone Application Use for Consultation in Emergency Medical Services
}

\author{
Korakot Apiratwarakul ${ }^{1,2}$, Takaaki Suzuki ${ }^{3}$, Ismet Celebi ${ }^{4}$, Somsak Tiamkao $^{5}$, Vajarabhongsa Bhudhisawasdi ${ }^{1}$, \\ Dhanu Gaysonsiri ${ }^{2,6}$, Kamonwon lenghong ${ }^{1,2 *}$ \\ ${ }^{1}$ Department of Emergency Medicine, Faculty of Medicine, Khon Kaen University, Khon Kaen, Thailand; ${ }^{2}$ Integrated Emergency \\ Medical Services and Pre-hospital Care Research Group, Faculty of Medicine, Khon Kaen University, Khon Kaen, Thailand; \\ ${ }^{3}$ Department of Emergency and Critical Care Medicine, University of Tsukuba Hospital, Tsukuba, Japan; ${ }^{4}$ Department of \\ Paramedic, Gazi University, Ankara, Turkey; ${ }^{5}$ Department of Medicine, Faculty of Medicine, Khon Kaen University, Khon Kaen, \\ Thailand; 6Department of Pharmacology, Faculty of Medicine, Khon Kaen University, Khon Kaen, Thailand
}

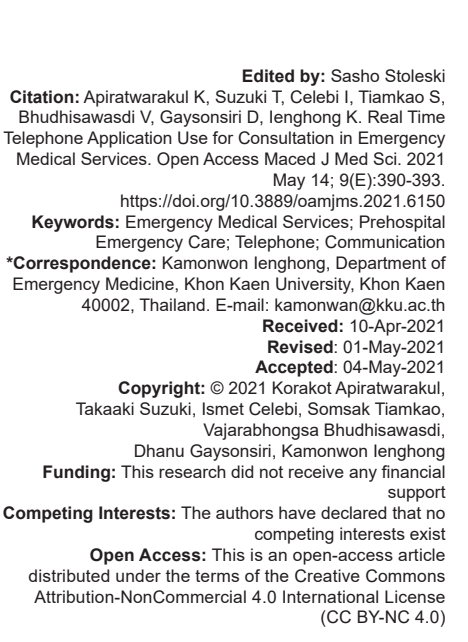

\section{Abstract}

BACKGROUND: Emergency medical services (EMS) are an operation that requires speed and prompt decisionmaking to provide patients treatment and rescue them from crisis. A telephone application was created to be communication channel. However, the effectiveness of EMS consulting through telephone application has not been well studied.

AIM: The aim of this study was to describe the use of real-time telephone application use for consultation in EMS METHODS: A cross-sectional, single EMS centered study at Srinagarind Hospital in Thailand. Data were gathered from LINE ${ }^{\circledR}$ Application under the name of "Current training EMKKU" and the EMS database throughout 2020-2021.

RESULTS: A total of 11550 messages with 6221 general text; messages were not involved in patients' consultant $(53.86 \%)$. The consultation mostly took place during the afternoon shifts (4 PM to 0 AM) accounted for $45.11 \%$. We found that Thursday (19.63\%) was the day with most frequent consulting services, followed by Tuesday $(16.05 \%)$ and Friday (16.03\%) regarding the consultation. There were 45 active users in the LINE ${ }^{\circledR}$ Application under the name of "Current training EMKKU." The mean age of the participants was $32.10 \pm 5.60$ years, and $51.11 \%(n=23)$ of them was female.

CONCLUSIONS: The real-time telephone application is used for consultation related to patients' symptoms during EMS operations and ER patient care was most commonly in the afternoon and on Thursdays and Tuesdays.

\section{Introduction}

Emergency medical services (EMS) are an operation that requires speed and prompt decisionmaking to provide emergency treatment to patients from crisis. The medical oversight of EMS is divided into direct and indirect aspects. In terms of direct medical oversight of EMS, telemedicine technology was used to coordinate information between the physicians serving in the hospitals with the operating personnel leaving for the scene of the incident. The previous study was found that the use of telehealth in EMS was rare in number when compared to other medical services [1]. Furthermore, the studies have shown that when telehealth was used in EMS, it resulted in reduced delivery to the emergency room (ER) by $6.7 \%$ and reduced time of the ambulance returning to hospitals for preparation by $44 \mathrm{~min}$. In the COVID-19 outbreak situation, studies have shown that it is $53.8 \%$ more likely to use telemedicine services through the WhatsApp ${ }^{\circledR}$ program and reduce time of travelling to the hospitals [2], [3]. However, the use of such technology must always be governed by ethical issues [4]. A study of the orthopedic consultation system found that $72 \%$ of the consultants were nondoctors and only $7 \%$ was physicians [5]. In previous studies, the consultation systems in various specialist at the ER were the primary duty of emergency physicians (EPs) to communicate effectively under the expectation of both patients and health-care professionals with both pressures and time constraints. Therefore, communication skills should be practiced while having a training related to emergency medicine resident program [6], [7].

In terms of Thailand EMS operations, there are personnel operating as EPs, emergency nurse practitioners, advance emergency medical technicians(EMTs), and EMTs who have the opportunity to use online consultation systems from 
outside hospital to provide accurate advice on how to best treat their patients and reduce ER delivery in mild cases [8], [9], [10]. Studies have shown that using the telephone for consultation is an easy-to-use device. It is convenient and reduces repetitive work as well [11], [12], [13]. As for the EMS, Srinagarind Hospital provides a $24-h$ service in the operating area covering almost half of Mueang District, Khon Kaen Province $\left(15^{\text {th }}\right.$ largest city area in Thailand). In the operations by the Khon Kaen EMS Dispatch Center to be categorized resuscitation patients (red color from telephone based dispatch), there will be a $1^{\text {st }}$-year-to- $3^{\text {rd }}$ year emergency medicine resident training with at least one person in all EMS operation. In the event of an EMS problem that needs to be consulted on patient care, there will be a communication channel through LINE $^{\circledR}$ Application under the name of "Current training EMKKU" which has a regular EPs instructor to give advice all the time. There are currently 45 members of the channel. The study on using mobile applications for consultation with an EMS operation will benefit in the design and development of a patient service system with highest efficiency.

\section{Methods}

\section{Study design and setting}

This was a cross-sectional, single EMS centered study at Srinagarind Hospital, Thailand. Data were gathered from LINE ${ }^{\circledR}$ Application under the name of "Current training EMKKU" and the EMS database throughout 2020-2021. Ethical approval was provided by the Khon Kaen University Ethics Committee for Human Research (HE641203). The requirement for informed consent was waived since confidentiality protection had already been guaranteed. Accordingly, participants were not identified by name, but instead by a unique study number.

\section{Participants and data collection}

Chat room was created on March 6, 2020, by EPs instructor under the name "Current training EMKKU," which is used as a 24-h channel for consultation of the patient's symptoms for emergency medicine resident training while conducting EMS.

We gathered all messages communicated in this channel from March 6, 2020, to March 6, 2021, in the LINE $^{\circledR}$ Application and convert them to text, and then trained research assistants (Bachelor's degree) classified all texts into three types: (1) General texts, (2) text messages for consultation of patient symptoms while in the ER, and (3) messages to discuss the symptoms of patients during EMS operations, with review by two EPs instructor to confirm the types of messages.

\section{Sample size and statistical analysis}

Based on the previous study in prevalence of EMS operations [14], the sample size was calculated. To achieve a significance level of 0.05 , power of test of $80 \%$ and absolute precision 0.02 , we determined that a sample size of 1801 would be required. Statistical analysis was performed with Khon Kaen University license (SPSS Inc., Chicago, IL, USA) by IBM SPSS for Windows version 26.0. Categorical data were presented as percentages, with continuous data presented employing mean and standard deviation. Univariable analysis was carried out using a two sample t-test for numerical data and Pearson's correlation for data relationships between groups.

\section{Results}

In the 1-year data collection (March 6, 2020 - March 6, 2021), there were 45 active users in the $\mathrm{LINE}^{\circledR}$ Application under the name of "Current training EMKKU", and the characteristics of which are shown in Table 1. The mean age of the participants was $32.10 \pm 5.60$ years, and $51.11 \%(n=23)$ of them was female. The most common roles in EMS members were EPs instructor accounted for $31.11 \%$ followed by years $1^{\text {st }}$ to $3^{\text {rd }}$ emergency medicine resident $(20.00 \%$ each).

Table 1: Characteristics of the subjects

\begin{tabular}{ll}
\hline Characteristics $(\mathrm{n}=45)$ & Number $(\%)$ \\
\hline Age (years) mean \pm SD & $32.10 \pm 5.60$ \\
Gender: female & $23 / 45(51.11)$ \\
Role in EMS members & $45(100.00)$ \\
EPs instructor & $14(31.11)$ \\
$1^{\text {st }}$ year emergency medicine resident & $9(20.00)$ \\
$2^{\text {nd }}$ year emergency medicine resident & $9(20.00)$ \\
$3^{\text {rd }}$ year Emergency medicine resident & $9(20.00)$ \\
Administrator & $4(8.89)$ \\
\hline SD: Standard deviation, EMS: Emergency medical services, EPs: Emergency physicians.
\end{tabular}

The observation of overall messages in telephone application "Current training EMKKU" revealed a total of 11550 messages with 6221 general text; messages not involved in patients consultant (53.86\%), as shown in Table 2 . The consultation mostly took place during the afternoon shifts (4 PM to $0 \mathrm{AM}$ ) $(45.11 \%)$. When analyzing the days of consultant, we found that Thursday (19.63\%) was the day with most consulting services, followed by Tuesday (16.05\%) and Friday $(16.03 \%)$, respectively.

The analysis of factors that affect EMS consultant in application (Table 3 ) revealed that female $(P=0.012)$, emergency medicine resident $(P<0.001)$, and afternoon shift $(P=0.014)$ are factors that significantly affect EMS consultant. 
Table 2: Characteristics of the chat messages

\begin{tabular}{ll}
\hline Characteristics $(\mathrm{n}=11550)$ & Number $(\%)$ \\
\hline Overall messages & $11550(100.00)$ \\
General text & $6221(53.86)$ \\
ER consult & $3110(26.93)$ \\
EMS consult & $2219(19.21)$ \\
Consultation time & \\
Morning shift & $3544(30.69)$ \\
Afternoon shift & $5210(45.11)$ \\
Night shift & $2796(24.20)$ \\
Days of consultant & \\
Sunday & $1204(10.42)$ \\
Monday & $1614(13.97)$ \\
Tuesday & $1854(16.05)$ \\
Wednesday & $1836(15.90)$ \\
Thursday & $2267(19.63)$ \\
Friday & $1851(16.03)$ \\
Saturday & $924(8.00)$ \\
\hline ER: Emergency room, EMS: Emergency medical services. &
\end{tabular}

Table 3: Factors affecting EMS consultant in application

\begin{tabular}{llll}
\hline Factors $(\mathrm{n}=2219)$ & Action $(\%)$ & Not action $(\%)$ & $\mathrm{p}$-value \\
\hline Female & $1562(70.39)$ & $657(29.61)$ & $0.012^{*}$ \\
Emergency medicine resident & $2006(90.40)$ & $213(9.60)$ & $<0.001^{*}$ \\
Afternoon shift & $1511(68.09)$ & $708(31.91)$ & $0.014^{*}$ \\
\hline${ }^{*}$ Statistical significance & & &
\end{tabular}

* *tatistical significance.

\section{Discussion}

This study was a telephone application use in the Line ${ }^{\circledR}$ program under the name "Current training EMKKU" which is employed as a communication channel between trained doctors in emergency medicine and EPs instructor to discuss problems during patient care. Out of the 11550 communications, nearly half of all messages are related to patient care at the $\mathrm{ER}$ and in the EMS. This is consistent with previous studies in various fields of communication. There will be correspondence of information both relevant and irrelevant to the patients [8], [9].

Most of the consultation time was afternoon shift, which was in accordance with the previous studies that had a higher number of afternoon EMS operations than any other shifts [14], [15], [16], [17]. Furthermore, during the afternoon, there is only one EPs left to the ER department, unlike the morning shift with the EPs at two to four staffs which can direct communication without using the consultation through the application.

We also found that as for days with highest frequency of consulting services, it is most common on Thursday, followed by Tuesday. This corresponds to the teaching model of the training physicians in the field of emergency medicine which in both days there will be academic activities in which all physicians will be required to acquire theoretical and practical knowledge. All medical examinations are the responsibility of the EPs instructor. Thus, the EMS information is communicated through a Line ${ }^{\circledR}$ application, which once a clinician completes the academic activity, he/she can track the patient's information immediately.

When studying the factors affecting the use of telephone application for consultation during patient care, the researcher found that the female gender, emergency medicine resident and operation in the afternoon shift are all related to the use of telephone applications for problem discussion during EMS care, thus developing a communication channel with real time telemedicine that can visualize the whole picture, voice, and two-way communication will be effective for providing useful advice to EMS operators.

However, this study contained some limitations, including information available from a single hospital that may differ in aspects of patient type or the training style of emergency medicine physicians. In addition, the present research's pattern is a retrospective study that may not contain complete information [16], [17], [18].

\section{Conclusion}

The real-time telephone application is used for consultation regarding patients' symptoms during EMS operations and ER patient care were most common in the afternoon and on Thursdays and Tuesdays.

\section{Acknowledgments}

The authors would like to express our sincere gratitude to NYC Language Institute (reference number: IV2020020172) for acting as an English consultant.

\section{References}

1. Langabeer JR $2^{\text {nd }}$, Champagne-Langabeer T, Alqusairi D, Kim J Jackson A, Persse D, et al. Cost-benefit analysis of telehealth in pre-hospital care. J Telemed Telecare. 2017;23(8):747-51. https://doi.org/10.1177/1357633x16680541 PMid:27913657

2. Kaliyadan F, Al Ameer MA, AI Ameer A, Al Alwan Q. Telemedicine Practice in Saudi Arabia During the COVID-19 Pandemic. Cureus. 2020;12(12):e12004. https://doi.org/10.7759/ cureus. 12004 PMid:33457115

3. Campagna S, Conti A, Dimonte V, Dalmasso M, Starnini M Gianino MM, et al. Trends and characteristics of emergency medical services in Italy: A 5-years population-based registry analysis. Healthcare (Basel). 2020;8(4):551. https://doi. org/10.3390/healthcare8040551

PMid:33322302

4. De Panfilis L, Merlo DF, Satolli R, Perin M, Ghirotto L, Costantini M. Clinical ethics consultation among Italian ethics committee: A mixed method study. PLoS One. 2019;14(12):e0226710. https:// doi.org/10.1371/journal.pone.0226710

PMid:31887158 
5. Kandel L, Barzilay Y, Friedman A, Ilsar I, Safran O, Mattan Y. Informal (Hallway) medical consultation in orthopedics-is it as common as it seems? Arch Orthop Trauma Surg. 2017;137(5):607-10. https://doi.org/10.1007/ s00402-017-2667-1

\section{PMid:28286926}

6. Baylis J, Miloslavsky EM, Woods R, Chan TM. Conquering consultations: A guide to advances in the science of referralconsultation interactions for residency education. Ann Emerg Med. 2019;74(1):119-25. https://doi.org/10.1016/j. annemergmed.2018.12.004

PMid:30661857

7. Wouda JC, van de Wiel HB. Supervisors' and residents' patienteducation competency in challenging outpatient consultations. Patient Educ Couns. 2015;98(9):1084-91. https://doi. org/10.1016/j.pec.2015.05.010 PMid:26074498

8. Bunn F, Byrne G, Kendall S. Telephone consultation and triage: Effects on health care use and patient satisfaction. Cochrane Database Syst Rev. 2004;(4):CD004180. https://doi. org/10.1002/14651858.cd004180

PMid: 15495083

9. Campbell JL, Fletcher E, Britten N, Green C, Holt T, Lattimer V, et al. The clinical effectiveness and cost-effectiveness of telephone triage for managing same-day consultation requests in general practice: a cluster randomised controlled trial comparing general practitioner-led and nurse-led management systems with usual care (the ESTEEM trial). Health Technol Assess. 2015;19(13):1-212. https://doi.org/10.3310/hta19130 PMid:25690266

10. Vaona A, Pappas Y, Grewal RS, Ajaz M, Majeed A, Car J. Training interventions for improving telephone consultation skills in clinicians. Cochrane Database Syst Rev. 2017;1(1):CD010034. https://doi.org/10.1002/14651858.cd010034.pub2

PMid:28052316
11. Downes MJ, Mervin MC, Byrnes JM, Scuffham PA. Telephone consultations for general practice: A systematic review. Syst Rev. 2017;6(1):128. https://doi.org/10.1186/s13643-017-0529-0 PMid:28673333

12. Eichler M, Blettner M. Telephone consultation-what standards should apply? Dtsch Arztebl Int. 2016;113(22-23):387-8. https:// doi.org/10.3238/arztebl.2016.0387.

PMid:27374374

13. $\mathrm{Wu} \mathrm{H}, \mathrm{Lu} \mathrm{N}$. Online written consultation, telephone consultation and offline appointment: An examination of the channel effect in online health communities. Int J Med Inform. 2017;107:107-19. https://doi.org/10.1016/j.ijmedinf.2017.08.009. PMid:29029686

14. Apiratwarakul $\mathrm{K}$, Songserm $\mathrm{W}$, lenghong $\mathrm{K}$, Phungoen $\mathrm{P}$, Gaysonsiri D, Bhudhisawasdi V. The Role of mechanical cardiopulmonary resuscitation devices in emergency medical services. J Med Assoc Thai. 2020;103(Suppl 6):98-101.

15. Apiratwarakul K, Songserm W, Bhudhisawasdi V, Wachirachiaranon P. Use of emergency medical services: Experience 100 days after first case of COVID-19. J Med Assoc Thai. 2021;104(Suppl 1): S5-7. https://doi.org/10.35755/ jmedassocthai.2021.S01.12123

16. lenghong $K$, Srikumpa $P$, Apiratwarakul $K$, Phungoen $P$, Gaysonsiri D, Bhudhisawasdi V. Factors associated with transfusion of uncross-matched type-O packed red cells for acute upper gastrointestinal hemorrhage. J Med Assoc Thai. 2020;103(Suppl 6):22-6

17. Apiratwarakul K, lenghong K, Gaysonsiri D, Mitsungnern $T$, Buranasakda M, Bhudhisawasdi V. The effectiveness of oxygen-powered inhalation devices in prehospital care. J Med Assoc Thai. 2020;103(Suppl 6):58-60.

18. lenghong K, Kleebbuakwan K, Apiratwarakul K, Phungoen $\mathrm{P}$, Gaysonsiri D, Bhudhisawasdi V. Comparison of cleaning methods for ultrasound probes at an emergency department in a resourcelimited country. J Med Assoc Thai. 2020;103(Suppl 6):67-71. 